\title{
Associations between healthy behaviors and coronary heart disease risk factors in women
}

\author{
Nagia Saleh $\mathrm{Ali}^{1}$, Cora Shonk ${ }^{2}$, Mahmoud Saleh El-Sayed ${ }^{3}$ \\ 1. Ball State University, United States. 2. Ivy Tech Community College, United States. 3. Formally with Liverpool John \\ Moores University, United Kingdom.
}

Correspondence: Nagia S. Ali. Address: Ball State University School of Nursing, 2000 University Avenue, Muncie, IN 47306, United States. Email: nali@bsu.edu.

Received: July 19, 2012

Accepted: August 17, 2012

Online Published: March 18, 2013

DOI : $10.5430 /$ jnep.v3n10p1

URL: http://dx.doi.org/10.5430/jnep.v3n10p1

\begin{abstract}
Objectives: To describe the heart-healthy behaviors in a convenience sample of 210 women from a Midwestern state in the US and examine the associations between the behaviors and having risk factors to coronary heart disease.

Methods: Logistic regression was used to examine the association between the behaviors of diet, exercise, and medication adherence with the risks of hypertension, hyperlipidemia, diabetes, family history of heart disease, and cigarette smoking.

Results: There were a low consumption of heart-healthy meals, inadequate exercise participation, and inadequate medications adherence. Having personal hyperlipidemia, a family history of heart disease, age and education were significantly associated with the behaviors.

Conclusion: The findings point to the need for evidence-based education aimed at increasing women's awareness of heart disease risks, improving their behaviors, and emphasizing the link between risk reduction and the behaviors.
\end{abstract}

\section{Key words}

Behaviors, Coronary heart disease, Women

\section{I ntroduction}

Although coronary heart disease (CHD) is believed to be a man's illness, it is the leading cause of death and disability in women, contributing to $51 \%$ of the total heart disease deaths in the United States (US) ${ }^{[1]}$. Despite the delayed occurrence of CHD in women than in men, survival data for women are alarming. Women are less likely to survive their first heart attack (HA) and more likely than men to die within one year of the diagnosis. The estimated direct and indirect costs of $\mathrm{CHD} / \mathrm{HA}$ is $\$ 177.1$ billion $^{[1]}$. At the time of CHD diagnosis, women usually have other conditions such as hypertension and obesity/diabetes; both of which increase women's morbidity and mortality. The risk of CHD among diabetic women is up to four times as high as non-diabetic women and there is a 7-fold higher mortality rate in hypertensive women with diabetes ${ }^{[2]}$.

Established risk factors of CHD include increasing age, having a male or a female relative with history of premature CHD, cigarette smoking, hypertension, hyperlipidemia, obesity, and diabetes. Other contributing risks include unhealthy diet, physical inactivity, and excessive alcohol consumption. In a worldwide research of 52 countries (INTERHEART study), 
cigarette smoking was the leading cause of $\mathrm{CHD}^{[3]}$. Women who smoke cigarettes lose the protective effect of estradiol and this predisposes them to have HA more than ten years earlier in life than nonsmokers ${ }^{[3]}$.

There is adequate evidence that lifestyle behaviors of ingesting healthy foods, losing weight if overweight or obese, regular physical activities, not smoking cigarettes, and consuming alcohol moderately or none can maintain heart health and decrease the incidence of an initial or a recurrent $\mathrm{HA}^{[4,5]}$. In the United Kingdom, the Epic Norfolk study showed that the cardiovascular mortality risk of women who practiced the 4 behaviors of no cigarette smoking, physical activity, moderate alcohol consumption, and consumption of at least 5 servings per day of fruits and vegetables was equivalent to being 14 years younger than women who practiced none ${ }^{[6]}$. Similarly, the Cochrane systemic review of 55 trials of multiple risk factors interventions for the prevention of CHD showed that risk factor can be reduced through changes in lifestyle behaviors ${ }^{[7]}$.

Obesity especially visceral obesity, diabetes, hyperlipidemia, and hypertension are, to a large extent, nutritionally induced conditions and a healthy diet is a fundamental behavior that addresses all of them simultaneously. It is generally accepted that weight loss in overweight and obese individuals is an important aspect of primary prevention of CHD. Another fundamental heart-healthy behavior is regular physical activities. Regular physical activities can reduce the risk of premature death from $\mathrm{CHD}^{[5]}$. Studies showed that regular physical activities are cardioprotective; they help to control body weight, hypertension, hyperlipidemia, and diabetes ${ }^{[5]}$.The third behavior that augments healthy diet and regular exercise is adherence to taking prescribed medications for the concomitant, chronic conditions associated with CHD. Although hyperlipidemia, hypertension, and diabetes are not curable conditions, they can be controlled by diet, exercise, and medication taking. Control of these chronic conditions will help delay the progress of cardiovascular disease and prevent further complications ${ }^{[8]}$.

Despite the abundance of literature on heart disease risk factors and the recommended behaviors, there is a gap in research regarding the connection between the combined heart-healthy behaviors and CHD risk factors in women. Previous studies of CHD have focused on either reducing a CHD risk factor or on a single lifestyle behavior such as diet or exercise ${ }^{[7,9,10]}$.

\section{Objectives}

The objectives were: (1) To describe the heart-healthy behaviors of diet, exercise, and medication adherence; (2) To examine the associations between the 3 behaviors and CHD risk factors of hypertension, hyperlipidemia, diabetes, cigarette smoking, and family history of heart disease.

\section{Materials and method}

The descriptive, predictive study used logistic regression to examine the associations between the heart-healthy behaviors and risk factor of CHD. Power analysis was used to estimate sample size ${ }^{[11]}$. Using power analysis table for multiple regression with alpha $=.05$, a standard power of .80 , moderate effect size, and 7 predictors (hypertension, hyperlipidemia, diabetes, family history of heart disease, cigarette smoking, education and age), the calculated sample size was 104.3.

Data were collected from a convenience sample of women church-goers in a Midwestern state in the US by an undergraduate assistant, after approval of the Institutional Review Boards. Questionnaires were anonymous. Inclusion criterion was age 40 years and older. Potential participants who agreed to participate were approached and handed the letter of explanation and the questionnaires. Of 150 questionnaires provided, 105 were returned. However, 20 were excluded because of missing data and ineligibility to the criterion of age. A total of 85 forms were included in the analysis. To increase sample size, data were collected from employees of 2 universities through liaison persons (faculty or staff). Liaison persons were provided with the anonymous forms in campus envelops and handed to participants who agreed to participate. Of 150 questionnaires distributed, 125 were returned and included in the final analysis. Questionnaires from 
church-goers were combined with those of university employees in one pool. Forms were not separated into two samples. The final number of completed questionnaires used in the analysis was 210.

The participants' characteristics sought were age, marital status, race, educational level, cigarette smoking, and alcohol consumption. Age was categorized into 4 categories: 40 - 44 years, 45 - 49, $50-54,55-59$ and more. For the purpose of including age in the logistic regression, age was collapsed into two categories, $<55$ that took 0 value and 55 and more coded as 1 . Marital status included 3 categories: single, married, and cohabit. Educational level included 4 categories: less than high school, high school, some college, and college degree. For the purpose of including education in logistic regression, educational level was collapsed into two categories, up to high school that took 0 value and more than high school, 1 value. Cigarette smoking was assessed by one question “Are you currently smoking any cigarettes?” Response option was yes as 1 value and no as 0 value. Alcohol consumption was assessed by asking participants to mark whether they consume any alcoholic beverages. If they marked yes, they were asked to mark the number of cans of beer, glasses of wine, and shot glasses of liquor they consume in an average week. The number of $g$ of alcohol from the three beverages were summed up and divided by seven to yield g of alcohol consumption per day. In the US, moderate alcohol consumption for women is one drink per day. A drink is $12 \mathrm{oz}$ can of beer, $5 \mathrm{oz}$ glass of wine, or $1.5 \mathrm{oz}$ of liquor and each equals $10 \mathrm{~g}$ of alcohol.

Having the personal risks of hypertension, hyperlipidemia, and diabetes were assessed by asking participants whether they were currently receiving prescribed medications for each of these chronic conditions (yes/no) and this identified them as currently having the condition. Participants were also asked whether they have a family history (parent or sibling) of heart disease (yes/no). Each yes took 1 value and each no took 0 value. Overweight/obesity as a risk factor of CHD was not assessed in this study for the following reasons. Participants self-report of their body weight would yield inaccurate, subjective responses. Although waist circumference is a reliable measure of visceral fat, it could not have been ascertained because of the nature of this descriptive study. Likewise, body mass index as a measure of total body fat could not have been obtained in this descriptive study.

Heart-healthy behaviors were assessed by 3 measures: food choices (FCs), exercise participation, and adherence to prescribed medications. The FCs measure was developed by converting the American Heart Association Dietary Guidelines ${ }^{[12]}$ recommended for heart health into 9 FC statements. The 9 FC statements were constructed with 4 scales: rarely, sometimes, often, and very often. For the purpose of using FCs in logistic regression, the four scales for each item were collapsed into two categories, less frequently (rarely and sometimes) that took 0 value and frequently (often and very often) that took 1 value. The full statements of the FCs appear in Table 1. Each item of the 9 FCs was treated as a separate dependent variable.

Table 1. Characteristics of women in the heart-healthy behaviors study

\begin{tabular}{|c|c|c|}
\hline Variable & $\mathbf{N}$ & $\%$ \\
\hline \multicolumn{3}{|l|}{ Race } \\
\hline White & 190 & 91.8 \\
\hline African American & 7 & 3.4 \\
\hline Others & 10 & 4.8 \\
\hline \multicolumn{3}{|l|}{ Educational levels } \\
\hline Up to high school & 94 & 45.4 \\
\hline >High school (college level) & 138 & 54.6 \\
\hline \multicolumn{3}{|l|}{ Age, years } \\
\hline$<55$ & 89 & 43.0 \\
\hline$\geq 55$ & 118 & 57.0 \\
\hline \multicolumn{3}{|l|}{ Marital status } \\
\hline Single & 48 & 23.5 \\
\hline Married & 143 & 70.1 \\
\hline Living with others & 13 & 6.4 \\
\hline
\end{tabular}


Table 1. (continued)

\begin{tabular}{|c|c|c|}
\hline Variable & $\mathbf{N}$ & $\%$ \\
\hline \multicolumn{3}{|l|}{ Alcohol consumption } \\
\hline Yes & 79 & 33.7 \\
\hline No & 131 & 61.3 \\
\hline \multicolumn{3}{|l|}{ Food choices (FCs) } \\
\hline \multicolumn{3}{|c|}{ 1.I eat 5 or more servings of fruits and vegetables, daily } \\
\hline Less frequently & 131 & 62.4 \\
\hline Frequently & 79 & 37.6 \\
\hline \multicolumn{3}{|c|}{ 2.I eat 6 servings of grains, whole grains and high fibers, daily } \\
\hline Less frequently & 158 & 76.4 \\
\hline Frequently & 49 & 23.6 \\
\hline \multicolumn{3}{|c|}{ 3.I eat foods with less saturated fat, cholesterol, hydrogenated fat, daily } \\
\hline Less frequently & 136 & 64.8 \\
\hline Frequently & 74 & 35.2 \\
\hline \multicolumn{3}{|c|}{ 4.I eat foods that are low in salt, daily } \\
\hline Less frequently & 138 & 65.7 \\
\hline Frequently & 72 & 34.3 \\
\hline \multicolumn{3}{|c|}{ 5.I eat at least 2 oily fish meals per week, weekly } \\
\hline Less frequently & 174 & 83.3 \\
\hline Frequently & 35 & 16.7 \\
\hline \multicolumn{3}{|c|}{ 6.I avoid adding salt on the table, daily } \\
\hline Less frequently & 110 & 52.7 \\
\hline Frequently & 99 & 47.3 \\
\hline \multicolumn{3}{|c|}{ 7.I review food labels to determine sodium and fat content, when shopping } \\
\hline Less frequently & 143 & 68.1 \\
\hline Frequently & 67 & 31.9 \\
\hline \multicolumn{3}{|c|}{ 8.I order meals that are low in fat, cholesterol, and sodium, when dine out } \\
\hline Less frequently & 169 & 61.7 \\
\hline Frequently & 41 & 19.5 \\
\hline \multicolumn{3}{|c|}{ 9.I minimize the intake of beverages and foods with added sugar, daily } \\
\hline Less frequently & 129 & 61.7 \\
\hline Frequently & 80 & 38.3 \\
\hline \multicolumn{3}{|l|}{ Exercise participation } \\
\hline Yes & 103 & 49.0 \\
\hline No & 107 & 51.0 \\
\hline \multicolumn{3}{|l|}{ Medications adherence } \\
\hline$<$ Below the median & 111 & 55.5 \\
\hline$\geq$ Median and above & 89 & 44.5 \\
\hline \multicolumn{3}{|c|}{$\overline{\text { Current risk factors to } \mathrm{CHD}}$} \\
\hline \multicolumn{3}{|l|}{ Hypertension } \\
\hline Yes & 126 & 60.0 \\
\hline No & 84 & 40.0 \\
\hline \multicolumn{3}{|l|}{ Hyperlipidemia } \\
\hline Yes & 82 & 39.0 \\
\hline No & 128 & 61.0 \\
\hline \multicolumn{3}{|l|}{ Diabetes } \\
\hline Yes & 47 & 22.4 \\
\hline No & 163 & 77.6 \\
\hline \multicolumn{3}{|c|}{ Family history of heart disease } \\
\hline Yes & 125 & 59.5 \\
\hline No & 85 & 40.5 \\
\hline \multicolumn{3}{|l|}{ Smoking cigarettes } \\
\hline Yes & 56 & 26.1 \\
\hline No & 154 & 73.9 \\
\hline
\end{tabular}

Exercise participation was assessed by asking participants whether they were physically active for the purpose of exercise such as walking, swimming, and cycling. If they checked yes, they were asked to mark the average number of days they 
exercised per week. Then they marked the average duration of exercise spent per day. To obtain an exercise score among those who were physically active, the number of days of exercise per week was multiplied by the number of minutes spent in exercise per day. This assessment method yielded a score of minutes spent in exercise per week. For the purpose of using exercise in logistic regression, exercise participation as yes/no option was used in the analysis. Yes took 1 value and no took 0 value.

Adherence to taking prescribed medications was assessed by one question "How regular do you take your prescribed medications?” Response options were rarely as 1 , sometimes 2 , often 3 , and routinely 4 . For the purpose of using logistic regression, medication adherence was re-coded from a continuous variable to 2 categories-variable using the median score. Category 1 included "below the median", that took 0 value, and category 2 "the median and above", that took 1 value.

A total of 5 CHD risk factors (hypertension, hyperlipedemia, diabetes, family history of heart disease, and cigarette smoking) and 2 demographic variables, age and education were used as predictors to examine the behaviors of 1) 9 FCs, 2) exercise participation, and 3) adherence to prescribed medication. The SPSS version 18.0 (SPSS, Chicago, IL) was used to do the analyses. The first logistic regression models run were for each of the $9 \mathrm{FCs}$; the second was for exercise participation, and the third was for adherence to prescribed medications.

\section{Results}

Descriptive results for the 210 women appear in Table 1. The majority of the sample was white, married, with more than half reporting more than high school education, and also more than half reporting being 55 years of age and above. One-third of participants reported alcohol consumption, with a mean of $7.233 \mathrm{~g} / \mathrm{day}(\mathrm{SD}=4.514)$. Current CHD risk factors of participants included hypertension, hyperlipidemia, diabetes, family history of heart disease, and cigarette smoking. Descriptive results of the heart-healthy FCs showed that participants had a low consumption of most of the heart-healthy meals. For example, there was only $16.7 \%$ who reported frequent consumption of two oily fish meals per week, and 23.6\% reported frequent consumption of whole grains and high fiber foods. Regarding exercise participation, less than half of participants were physically active and the average duration of physical activity was less than the recommended 150 minutes per week $(M=103.70$ minutes, $S D=68.44)$. Adherence to prescribed medications showed that less than half of participants have the median score or higher.

Results of the logistic regression models of the 9 FCs are presented in Table 2. Education and age were significant predictors of most food choices. Hyperlipidemia was significantly associated with the consumption of at least two oily fish meals per week. Also, having a family history of heart disease was significantly associated with the consumption of meals that have low saturated/hydrogenated fat and cholesterol and also with reviewing food labels for fat and salt content. Having hypertension, diabetes, and cigarette smoking were not significantly associated with any of the heart-healthy FCs.

Odd ratio results for exercise and CHD risks appear in Table 3. Women who participated in physical activities for the purpose of exercise were significantly more likely to have higher educational level and aged 55 years and older. Having hypertension, hyperlipidemia, diabetes, family history of heart disease, and cigarette smoking were not significantly associated with exercise participation.

Odd ratio results for medication adherence and CHD risks appear in Table 4.Women who had the "median score or higher" of adherence to prescribed medications were significantly more likely to have a family history of heart disease and higher education level. Having hypertension, hyperlipidemia, diabetes, and cigarette smoking were not significantly associated with medication adherence. 
Table 2. Odd ratios for food choices and coronary heart disease risk factors

\begin{tabular}{|c|c|c|}
\hline Risk Factors and Food Choices & OR (95\% CI) & $P$-Value \\
\hline \multicolumn{3}{|l|}{ Consumption of vegetables/fruits } \\
\hline Hypertension & $1.27(0.63,2.57)$ & 0.50 \\
\hline Hyperlipidemia & $1.53(0.76,3.07)$ & 0.23 \\
\hline Diabetes & $1.37(0.61,3.11)$ & 0.44 \\
\hline Family history of heart disease & $0.60(0.31,1.16)$ & 0.13 \\
\hline Cigarette smoking & $1.48(0.69,3.18)$ & 0.31 \\
\hline Education & $2.74(1.39,5.41)$ & 0.00 \\
\hline Age & $1.88(0.99,3.55)$ & 0.05 \\
\hline \multicolumn{3}{|l|}{ Consumption of whole grains/fibers } \\
\hline Hypertension & $0.78(0.35,1.75)$ & 0.55 \\
\hline Hyperlipidemia & $2.14(0.94,4.84)$ & 0.06 \\
\hline Diabetes & $1.09(0.42,2.85)$ & 0.85 \\
\hline Family history of heart disease & $0.54(0.25,1.17)$ & 0.12 \\
\hline Cigarette smoking & $1.48(0.69,3.18)$ & 0.16 \\
\hline Education & $2.65(1.18,5.91)$ & 0.01 \\
\hline Age & $2.43(1.14,5.18)$ & 0.02 \\
\hline \multicolumn{3}{|l|}{ Consumption of less saturated fat, cholesterol } \\
\hline Hypertension & $1.04(0.49,2.16)$ & 0.93 \\
\hline Hyperlipidemia & $1.81(0.87,3.73)$ & 0.11 \\
\hline Diabetes & $0.94(0.42,2.12)$ & 0.88 \\
\hline Family history of heart disease & $0.44(0.22,0.88)$ & 0.02 \\
\hline Cigarette smoking & $1.48(0.67,3.27)$ & 0.34 \\
\hline Education & $2.47(1.22,5.03)$ & 0.01 \\
\hline Age & $4.00(1.99,8.03)$ & 0.00 \\
\hline \multicolumn{3}{|l|}{ Consumption of low salt meals } \\
\hline Hypertension & $1.03(0.51,2.07)$ & 0.94 \\
\hline Hyperlipidemia & $1.10(0.55,2.17)$ & 0.79 \\
\hline Diabetes & $1.41(0.63,3.13)$ & 0.40 \\
\hline Family history of heart disease & $1.03(0.54,1.94)$ & 0.94 \\
\hline Cigarette smoking & $1.13(0.54,2.36)$ & 0.75 \\
\hline Education & $1.86(0.94,3.66)$ & 0.74 \\
\hline Age & $2.48(1.30,4.72)$ & 0.00 \\
\hline \multicolumn{2}{|l|}{ Consumption of 2 oily fish meals per week } & \\
\hline Hypertension & $0.89(0.36,2.20)$ & 0.80 \\
\hline Hyperlipidemia & $3.81(1.30,11.13)$ & 0.02 \\
\hline Diabetes & $1.71(0.51,5.74)$ & 0.39 \\
\hline Family history of heart disease & $1.72(0.74,3.95)$ & 0.21 \\
\hline Cigarette smoking & $3.43(0.95,12.44)$ & 0.06 \\
\hline Education & $1.57(0.64,3.80)$ & 0.33 \\
\hline Age & $1.77(0.77,4.07)$ & 0.18 \\
\hline \multicolumn{3}{|l|}{ Avoiding the addition of salt on the table } \\
\hline Hypertension & $0.97(0.50,1.91)$ & 0.94 \\
\hline Hyperlipidemia & $1.10(0.57,2.11)$ & 0.78 \\
\hline Diabetes & $1.51(0.72,3.18)$ & 0.27 \\
\hline Family history of heart disease & $0.80(0.43,1.48)$ & 0.48 \\
\hline Cigarette smoking & $1.24(0.62,2.49)$ & 0.54 \\
\hline Education & $2.02(1.06,3.85)$ & 0.03 \\
\hline Age & $2.21(1.21,4.03)$ & 0.01 \\
\hline Reviewing of food label when shopping & & \\
\hline Hypertension & $1.21(0.59,2.51)$ & 0.60 \\
\hline Hyperlipidemia & $1.65(0.80,3.37)$ & 0.17 \\
\hline Diabetes & $1.24(0.54,2.86)$ & 0.61 \\
\hline Family history of heart disease & $0.51(0.26,1.01)$ & 0.05 \\
\hline Cigarette smoking & $1.13(0.52,2.45)$ & 0.76 \\
\hline Education & $1.80(0.90,3.62)$ & 0.10 \\
\hline Age & $2.95(1.49,5.82)$ & 0.00 \\
\hline
\end{tabular}


Table 2. (continued)

\begin{tabular}{lll}
\hline Risk Factors and Food Choices & OR $(\mathbf{9 5} \% \mathbf{C I})$ & P-Value \\
\hline Ordering of healthy foods when dinning out & & 0.80 \\
Hypertension & $1.12(0.47,2.67)$ & 0.49 \\
Hyperlipidemia & $1.37(0.56,3.34)$ & 0.36 \\
Diabetes & $1.70(0.55,5.22)$ & 0.62 \\
Family history of heart disease & $1.24(0.54,2.81)$ & 0.68 \\
Cigarette smoking & $1.25(0.44,3.56)$ & 0.00 \\
Education & $4.45(1.73,11.45)$ & 0.00 \\
Age & $8.41(3.00,23.58)$ & 0.63 \\
Minimizing drinks with added sugar & & 0.76 \\
Hypertension & $1.19(0.58,2.43)$ & 0.97 \\
Hyperlipidemia & $1.12(0.55,2.25)$ & 0.07 \\
Diabetes & $0.99(0.44,2.19)$ & 0.07 \\
Family history of heart disease & $0.55(0.29,1.07)$ & 0.00 \\
Cigarette smoking & $2.15(0.98,4.73)$ & 0.03 \\
Education & $3.04(1.52,6.07)$ & \\
Age & $2.07(1.09,3.94)$ & \\
\hline
\end{tabular}

Table 3. Odd ratios for exercise participation and coronary heart disease risk factors

\begin{tabular}{lll}
\hline Risk factors & OR (95\% CI) & P-value \\
\hline Hypertension & $0.98(0.48,2.02)$ & 0.97 \\
Hyperlipidemia & $0.75(0.38,1.49)$ & 0.41 \\
Diabetes & $0.96(0.44,2.11)$ & 0.92 \\
Family history of heart disease & $1.33(0.69,2.54)$ & 0.39 \\
Cigarette smoking & $0.61(0.30,0.45)$ & 0.18 \\
Education & $0.23(0.12,0.45)$ & 0.00 \\
Age & $0.42(0.22,0.79)$ & 0.01 \\
\hline
\end{tabular}

Table 4. Odd ratios for adherence to prescribed medications and coronary heart disease risk factors

\begin{tabular}{lll}
\hline Risk factors & OR (95\% CI) & P-value \\
\hline Hypertension & $1.72(0.83,3.59)$ & 0.15 \\
Hyperlipidemia & $1.01(0.50,2.03)$ & 0.97 \\
Diabetes & $1.61(0.72,3.59)$ & 0.24 \\
Family history of heart disease & $0.40(0.20,0.79)$ & 0.01 \\
Cigarette smoking & $2.04(0.94,4.43)$ & 0.06 \\
Education & $3.04(1.54,5.99)$ & 0.00 \\
Age & $1.47(0.77,2.82)$ & 0.42 \\
\hline
\end{tabular}

\section{Discussion}

The practice of heart-healthy behaviors of diet, exercise, and adherence to medication was low. Women smoked cigarettes, inadequately consumed heart-healthy meals, exercised insufficiently or performed no exercise, and reported inadequate adherence to prescribed medications. Although the pattern of cigarette smoking as daily or socially was not examined in this study, any cigarette smoking has a negative influence on the cardiovascular system ${ }^{[13]}$. Previous studies showed that women who smoke cigarettes may not pay greater attention to healthy behaviors as nonsmoking women do ${ }^{[13,14]}$.Since cigarette smoking is the most prominent risk factor to CHD in young women, intensive efforts need to focus on helping women stop smoking.

Although hypertension, hyperlipidemia, diabetes, family history of heart disease, and cigarette smoking were evident risks of CHD in this sample, alcohol consumption was not. In general, diet, exercise, and adherence to medications are behaviors undertaken to promote wellness and to prevent many chronic conditions, including CHD. Nevertheless, the behaviors were not adopted by women. The reasons for that are not clear from this study. It is possible that women might not understand the importance of practicing heart-healthy behaviors in reducing CHD risks, because the disease might not 
happen to them. They may underestimate their personal risks or they may lack the information about the connection between risks and the development of the disease. Since women with CHD may remain asymptomatically for a certain period of time, education about prevention can be a challenge. Educational strategies delivered by nurses and designed to highlight the link among healthy behaviors, risk factor reduction, and the development of CHD need to be intensified and consistently followed up.

Education and age were consistently associated with food choices, exercise participation, and adherence to prescribed medication. Although both variables are personal characteristics/demographics that are not amenable to intervention, they can be used to tailor health educational messages to the target audience. Hyperlipidemia and a family history of heart disease were associated with some food choices. People may have it clear in their mind that a healthy diet will reduce their chances of developing the disease since they already have a family history of it and already taking medications to reduce their lipid levels. It is also possible that women with these conditions might have been told by their health care providers that they are at risk to develop CHD and therefore were attentive to modify their food choices. Other plausible reasons might include mass media effect, knowledge acquisition through the Internet, and/or having a partner who shares the same behaviors.

A disturbing finding in this study is that being hypertensive, diabetic, and hyperlipidemic were not associated with the tested heart-healthy behaviors. In partial agreement with these results, an earlier report indicating that women with hypertension, but not those with hyperlipidemia or diabetes, were more attentive to practice CHD preventive behaviors ${ }^{[15]}$. Similarly, a longitudinal study showed that the practices of healthy behaviors of women with hypertension, diabetes, and hyperlipidemia were not different from those without these chronic conditions ${ }^{[14]}$. Health education interventions need to emphasize the link between the behaviors and CHD risks. It is recommended that intervention strategies should be consistently maintained in the long term to be efficacious and cost effective in reducing CHD mortality ${ }^{[7]}$.

Lack of association between exercise and CHD risk factors is difficult to explain. Since more than half of participants were sedentary, their exercise participation may have not been adequately represented to be predicted. Also, participants may have not conceptually linked exercise to a reduction in the CHD risks. Health promotion messages need to address exercise individually and as a community issue. Adherence to prescribed medications was associated with having a family history of heart disease, but not with being hypertensive, hyperlipidemic, and/or diabetic. In fact, a recent study reported that adherence to cardiovascular preventive medications can be hindered because of a complex regimen with multiple medications taking and multiple dosing schedules ${ }^{[16]}$. Additionally, adverse effects and low perceptions of medicinal efficacy of cardiovascular drugs may profoundly affect adherence ${ }^{[17]}$. Promotion of adherence to medications taking need to address drugs used for each chronic condition, adverse effects, and perceptions of drug efficacy.

\section{Limitations}

Limitations to interpreting the study's results include a convenience sample drawn from one Midwestern state in the US, which is largely white. Combining church-goers with university employees in one pool is another limitation that deterred the examination of each group demographics and personal characteristics, separately. Also, lack of assessing weight/ obesity in the study is a limitation. Half of the sample reported more than high school education and this may have shifted the results in favor of education as a predictor. The study is also limited by the self-report method used to collect data, which may have resulted in biased report. Furthermore, the assessment of adherence to taking prescribed medications was ascertained as a general question rather than a specific one for each chronic condition.

\section{Conclusion}

Lack of associations found between heart-healthy behaviors and CHD risk factors points to the need for evidence-based education aimed at increasing women's awareness of their own CHD risk factors and emphasizing the link between risk 
reduction and the behaviors. Further research is needed to use evidence-based research in implementing intensive health education strategies.

\section{References}

[1] American Heart Association, the Writing Group Members. Heart disease and stroke statistics 2010 Update: a report from the American Heart Association. Circulation. 2010; 121: 948-954. PMid:20177011

http://dx.doi.org/10.1161/CIRCULATIONAHA.109.192666

[2] Wenger N. Preventing cardiovascular disease in women: an update. Clin Cardiol. 2008; 3: 109-113. PMid:17803222 http://dx.doi.org/10.1002/clc.20134

[3] Yusuf S, Hawken S, Ounpuu S, Dans T, Avezum A, Lana F, McQueen M, Budaj A, Pais P, Varigo J, Lisheng L. Effect of potentially modifiable risk factors associated with myocardial infarction in 52 countries (INTERHEART study): case-control study. Lancet. 2004; 364: 937-952. http://dx.doi.org/10.1016/S0140-6736 (04)17018-9

[4] Mente A, de Koning L, Shannon H, Anand S. A systematic review of the evidence supporting a causal link between dietary factors and coronary heart disease. Arch Intern Med. 2009; 169: 659-669. PMid:19364995

http://dx.doi.org/10.1001/archinternmed.2009.38

[5] Mosca L, Banka C, Benjamin E. Evidence-based guidelines for the cardiovascular disease prevention in women: 2007 update. Circulation. 2007; 115: 1481-1501. PMid:17309915 http://dx.doi.org/10.1161/CIRCULATIONAHA.107.181546

[6] Khaw k, Wareham N, Bingham S, Welch A, Luben R, Day N. Combined impact of health behaviours and mortality in men and women: the EPIC-Norfolk Prospective Population study. PLOS Medicine. 2008; 5. PMid:18184033 http://dx.doi.org/10.1371/journal.pmed.0050012

[7] Ebrahim S, Taylor F, Ward K, Beswick A, Burke M, Davey Smith G. Multiple risk factor interventions for primary prevention of coronary heart disease. Cochrane Database of Systemic Reviews. 2011. 1. Art No. CD001561. http://dx.doi.org/ 10.1002/14651858.CD001561.pub 3.

[8] Dimatteo M, Giordani P, Lepper HS, Croghan T. Patient adherence and medical treatment outcomes: a meta-analysis. Med Care. 2002; 40: 794-811. PMid:12218770 http://dx.doi.org/10.1097/00005650-200209000-00009

[9] Cicero AF, Dormi A, D’Addato S, Gaddi AV, Borghi C. Long-term effect of dietary education program on postmenopausal cardiovascular risk and metabolic syndrome: The Brisighella Heart Study. J Womens Health. 2010; 19: $133-137$. PMid:20088669 http://dx.doi.org/10.1089/jwh.2008.1268

[10] Carels RA, Darby L, Cacciapaglia HM, Douglass OM. Reducing cardiovascular risk factors in postmenopausal women through a lifestyle change intervention. J Womens Health. 2004; 13: 412-426. PMid:15186658 http://dx.doi.org/10.1089/154099904323087105

[11] Polit DF, Beck CT. Using multivariate statistics to analyze complex relationships. In Nursing Research: Generating and Assessing Evidence for Nursing Practice. 8th ed. Philadelphia, Wolter Kluwer, Williams and Wilkins. 2008; 614-641.

[12] Lichtenstein A, Appel L, Brand M, Carnethon M, Daniels S, Franch, H Franklin, B Kris-Etherton, P, Harris W, Howard B, Karanja N, Lefevre M, Rudel L, Sacks F, Horn L, Winston M, Wylie-Rosett J. Diet and lifestyle recommendations revision 2006: a scientific statement from the American Heart Association Nutrition Committee. Circulation. 2006; 114: 82-96. PMid:16785338 http://dx.doi.org/10.1161/CIRCULATIONAHA.106.176158

[13] Hassmiller K, Warner K, Mendez D, Levy D, Romano E. Nondaily smokers: Who are they? Am J of Public Health. 2003; 93: 1321-1327. PMid:12893622 http://dx.doi.org/10.2105/AJPH.93.8.1321

[14] King D, Mainous III A, Carnemolla M, Everett C. Adherence to healthy lifestyle habits in US adults, 1988-2006. Am J of Med. 2009; 122: 528-534. PMid:19486715 http://dx.doi.org/10.1016/j.amjmed.2008.11.013

[15] Ali N. Prediction of coronary heart disease preventive behaviors in women: a test of the health belief model. Women Health. 2002; 35: 83-96. http://dx.doi.org/10.1300/J013v35n01_06

[16] Choudhry N, Fischer M, Avorn J, Liberman J, Schneeweiss S, Pakes J. Brennan T, Shrank W. The implications of therapeutic complexity on adherence to cardiovascular medications. Arch Intern Med. 2011; 171: 814-822. http://dx.doi.org/10.1001/archinternmed.2010.495

[17] Fried T, Tinetti M, Towle V, OLeary J, Iannone L. Effects of benefits and harms on older persons' willingness to take medications for primary cardiovascular prevention. Arch Intern Med. 2011; 171: 923-928. PMid:21357797

http://dx.doi.org/10.1001/archinternmed.2011.32 